Relations industrielles

Industrial Relations

\title{
La sécurité syndicale en Angleterre
}

\section{Gérard Dion}

Volume 4, numéro 6, février 1949

URI : https://id.erudit.org/iderudit/1023477ar

DOI : https://doi.org/10.7202/1023477ar

Aller au sommaire du numéro

Éditeur(s)

Département des relations industrielles de l'Université Laval

ISSN

0034-379X (imprimé)

1703-8138 (numérique)

Découvrir la revue

Citer cet article

Dion, G. (1949). La sécurité syndicale en Angleterre. Relations industrielles /

Industrial Relations, 4(6), 57-58. https://doi.org/10.7202/1023477ar

Tous droits réservés (C Département des relations industrielles de l’Université Laval, 1949
Ce document est protégé par la loi sur le droit d'auteur. L'utilisation des services d'Érudit (y compris la reproduction) est assujettie à sa politique d'utilisation que vous pouvez consulter en ligne.

https://apropos.erudit.org/fr/usagers/politique-dutilisation/ 


\title{
LA SÉCURITÉ SYNDICALE EN ANGLETERRE
}

\author{
Gérard Dion
}

A cause des liens intimes qui existent entre le Canada et l'Angleterre, les institutions britanniques exercent une influence considérable sur celles de notre pays. Aussi il ne manque pas de personnes soi-disantes informées et réputées compétentes qui dans les discussions sur le problème de la sécurité syndicale affirment avec un sang-froid surprenant que l'atelier fermé n'existe pas en Angleterre. Le R.P. Jérome Toner, professeur de relations industrielles à St-Martin's College, Olympia, Washington, vient de publier une étude intéressante sur ce sujet: «The Closed Shop in Great Britain ». ${ }^{1}$

Le principe et la pratique de contraindre tous ceux qui se livrent à un commerce ou exercent un métier à adhérer à leur groupement professionnel comme condition sine qua non de leur travail furent acceptés depuis le 8ième jusqu'au 18ième siècle en Angleterre comme dans tous les autres pays d'Europe. On ne voyait aucun conflit entre le droit individuel au travail et les exigences du bien commun professionnel.

Ce n'est qu'en 1799, sous l'influence du libéralisme, que l'atelier fermé en même temps que le droit d'association disparaît par une mesure légale ( 39 , Geo. III, c. 81 ). Mais dès 1800 , la loi fut modifiée de façon à permettre aux travailleurs de « refuser de travailler avec un autre pour une cause juste et raisonnable». - C'est l'atelier fermé en pratique - Les sociétés fraternelles qui s'étaient formées après la disparition des guildes croyaient que le principe de l'atelier fermé était leur droit de naissance essayèrent de l'imposer même par la violence. Aussi en 1824 la loi qui vint légaliser l'existence des unions ouvrières dans une de ses sections interdisait la pratique de l'atelier fermé (5, Geo. IV, c. 95). Ainsi qu'il arrive souvent, les prohibitions légales, lorsqu'elles dépassent la mesure, produisent des effets contraires à ceux que le législateur se propose. Aussi comme le témoigne $\mathrm{W}$. T. Thornton, ${ }^{2}$ malgré les interdictions légales, l'atelier fermé continue d'exister et de se propager si bien, qu'en certains endroits le propriétaire d'une entreprise ne peut

(1) Jérome Tonen, The Closed Shop in Great Britain, une brochure 18 pages, Labor's Non-Partisan League, 907 Fifteenth St, N.W., Washington 5.

(2) W.T. Thonnton, On Labor, page 207. même pas embaucher son neveu, ni son frère sans qu'ils deviennent membres de l'union.

Durant la dernière moitié du 19ième siècle, l'opinion publique et les lois de 1867,1871 et 1875 tournèrent en faveur des unions ouvrières et permirent l'atelier fermé tel que conçu en Angleterre, c'est-à-dire le droit pour des ouvriers de refuser de travailler avec quelqu'un qui n'est pas membre de l'union. Il y eut des poursuites judiciaires à ce sujet et le Conseil Privé, dans le cas célèbre Allan vs Flood, confirma définitivement la pratique de l'atelier fermé. Elle devint alors si courante, entra tellement dans les moeurs que pour employer les termes de Sydney \& Beatrix Webb «cette contrainte cesse d'être apparente. Une personne n'appartenant pas à l'union n'ose même penser faire application pour une position ou aurait la chance d'en obtenir une ${ }^{3}{ }^{3}$

En 1927 après la grève générale des employés de transport, le Trade Disputes and Trade Union Act fut modifié pour bannir la pratique de l'atelier fermé dans les entreprises gérées par l'Etat; toutefois rien ne fut changé dans les autres entreprises et elle continua d'être générale partout ailleurs.

On sait qu'en 1946, le gouvernement travailliste a de nouveau amendé la loi et rétabli la légalité de l'atelier fermé pour toutes les entreprises, ce qui ne s'est pas accompli sans discussion. Cela est compréhensible car en Angleterre, contrairement à ce que nous avons ici au Canada, sous l'empire de la Loi sur les relations industrielles et sur les enquêtes visant les différends du travail (11-12 George VI, c. 54) et dans la province de Québec, avec la Loi des relations ouvrières (S.R.Q. 1941, 162-A), un syndicat n'a pas à être certifié et à posséder la majorité des travailleurs dans un établissement pour pouvoir traiter au nom de tous les employés. De plus, ce sont généralement des associations d'employeurs qui négocient les conventions collectives. Alors, pour la partie patronale la possibilité d'influencer le choix de l'union chez les travailleurs est-elle beaucoup plus grande ici. Ce qui amène pour conséquence que, les services publics étant sous la domination d'un parti travailliste et beaucoup d'in(3) Sydney \& Beatrix WEBB, Industrial Democracy, page
216. 
dustries de base étant nationalisées, on a parlé en certains milieux de la fascisation des unions ouvrières: «The written concensus of opponents of the closed shop seems to be that the child, which has grown up to be the Government, and which soon may be the largest employer in Great Britain, will use the closed shop through the Trades Union Congress to perpetuate itself and crush all opposition. ${ }^{4}$

Mais ce débat politique ne touche pas du tout les entreprises privées où l'atelier fermé reste toujours une pratique admise par tous au point qu'on ne prend même pas la peine de l'inclure comme une clause spéciale dans les conventions collectives de travail.

(4) Jérome TONER, op. cit. page 15.

\title{
LE SERVICE D'ÉdUCATION DE LA C.T.C.C.
}

\author{
Fernand Jolicoeur
}

La Confédération des Travailleurs Catholiques du Canada groupe aujourd'hui près de $\mathbf{9 0 , 0 0 0}$ membres. Il est devenu un lieu commun de dire que c'est maintenant le mouvement ouvrier le plus représentatif dans la province de Québec. Cette expansion continuelle est due à la compétence et au dévouement de ses organisateurs et techniciens autant qu'à la valeur des principes qui l'animent.

Devant ce fait accompli et l'avenir inconnu, le problème s'est posé pour la C.T.C.C. de consolider définitivement et sûrement ses positions acquises, puis d'orienter son action vers le seul but qu'elle doit poursuivre et qui peut lui assurer la vie, celui qu'indique la doctrine sociale de l'Eglise. Afin de préciser ce but, de le faire connaitre dans tout le mouvement ouvrier, et de former ses membres à le poursuivre «par la voie la plus aisée et la plus courte», la C.T.C.C. a fondé son propre Service d'Education.

On ne peut imaginer un mouvement syndical ouvrier, surtout un mouvement d'inspiration catholique, sans organisme de formation. D'ailleurs l'histoire de la C.T.C.C. prouve amplement qu'elle n'a pas dérogé à ce principe. Dès ses débuts, nous rencontrons des cercles d'études où se sont formés les chefs qui l'ont fait naître et grandir à sa taille actuelle.

A Québec, M. l'abbé Maxime Fortin, premier aumônier de la C.T.C.C., organisait vers 1915 , ce qu'il appelait la «Commission des Questions Ouvrières de l'Action Sociale Catholique ». A Montréal, M. l'abbé Edmour Hébert fondait, en 1918, avec l'aide de l'Ecole Sociale Populaire, le fameux cercle Léon XIII, considéré comme le premier cercle d'étude syndical du mouvement. Dans chaque région de la province, ces exemples furent suivis avec fruit et, vers 1938, se formait la «Fédération des Cercles d'Etudes» de la C.T.C.C. Cette dernière a fonctionné jusqu'en 1946, alors qu'on commença à songer à un organisme plus élaboré, plus à la portée des nouveaux besoins du monde ouvrier.

On chercha une formule et on attendit d'avoir les moyens financiers voulus pour mettre sur pied un véritable Service d'Education, où un «libéré 》 pourrait diriger le travail et orienter les études sur tous les plans nécessaires. Au congrès de la C.T.C.C. à Hull, en octobre 1948, le projet longtemps caressé prit enfin corps. Le Service d'Education de la C.T.C.C. était né et un officier du mouvement entrait en charge dès le début de novembre dernier.

$$
* \quad * \quad *
$$

Pour expliquer la nature et le rôle de ce nouveau service, il faut dire d'abord que ce n'est pas une école que la C.T.C.C. a voulu fonder, école où des professeurs dispenseraient une science à des élèves. Le Service d'Education sera plutôt un centre d'études en commun. Comme le nom le dit bien, ce sera un «service», service organisé à l'intérieur du mouvement lui-même pour orienter les études, les compiler, les diffuser; service auquel contribueront tous les chefs du mouvement et dont profiteront tous les ouvriers.

Ce nouveau service syndical ne devra pas se contenter de faire l'initiation syndicale, qui s'impose cependant, ni de former des négociateurs, mais surtout d'expliquer le sens profond du syndicalisme, le pourquoi et l'orientation essentielle du mouvement ouvrier.

Or la C.T.C.C. s'appuie sur la doctrine sociale de l'Eglise pour affirmer que la structure actuelle 